\title{
ESTAR MEASUREMENTS DURING SGP-99
}

\author{
D.M. Le Vine, M. Haken, S. Bidwell \\ Goddard Space Flight Center, Microwave Sensors Branch, Greenbelt, Maryland 20771 \\ C.T. Swift \\ Department of Electrical Engineering, University of Massachusetts, Amherst, MA 01003 \\ T. Jackson \\ USDA/ARS Hydrology Laboratory, Beltsville, Maryland 20705
}

The synthetic aperture radiometer, ESTAR, provided L-band brightness temperature maps of the experiment site during the Southern Great Plains Experiment in 1999. ESTAR flew on the NASA P-3 aircraft at an altitude of $7.6 \mathrm{~km}$ and mapped a swath about $50 \mathrm{~km}$ wide and about $300 \mathrm{~km}$ long. The area mapped extended west from Oklahoma City to El Reno and north from the Little Washita River watershed to the Kansas border. The flight lines and mapping were done in a manner similar to that used in 1997 during SGP-97.

ESTAR is a prototype designed to develop the technology of aperture synthesis for passive microwave remote sensing. It is actually a hybrid that uses real aperture to obtain resolution along track and synthetic aperture to obtain resolution across track. ESTAR operates in the band at $1.413 \mathrm{GHz}$ set aside for passive use and images at horizontal polarization in the equivalent of a cross-track scan. The scan is done in software as part of image reconstruction. Calibration consists of blackbody observed before and after each flight and a local body of water (Lake Kaw).

ESTAR arrived in Oklahoma on July 7, 1999 and flew mapping missions on July $8,9,11,14,15,19$ and 20 . The aircraft was down on July 10 by design and was down again on July $12-13$ and 16-18 due to mechanical problems. ESTAR data for July 11 is questionable because of a hardware failure.

The brightness temperature maps reflect the patterns of soil moisture observed in the SGP99 study area and compare well with measurements made by ESTAR in other experiments in this region (e.g. SGP-97 and Washita-92).

Presentation: International Geoscience and Remote Sensing Symposium (IGARSS) July, 2000 